\title{
Exhumation of (U) HP/LT rocks caused by diachronous slab breakoff
}

\author{
D. Boutelier ${ }^{\mathrm{a}, *}$, A. Cruden ${ }^{\mathrm{b}}$ \\ ${ }^{a}$ School of Environmental and Life Sciences, University of Newcastle, Newcastle NSW, \\ Australia \\ ${ }^{b}$ School of Earth, Atmosphere E Environment, Monash University, Clayton VIC, Australia
}

\begin{abstract}
Three-dimensional thermo-mechanical analogue models investigate how diachronous slab breakoff may lead to the exhumation of subducted continental crust. Slab breakoff initiates spontaneously in one location and migrates laterally along the plate boundary, causing a transient excess downward pull force on the plate boundary in front of the propagating slab tear. This pull force locally reduces the pressure between the plates, which promotes buoyancy-driven exhumation of subducted crust. However, both the surface area undergoing the pressure reduction and its duration are limited. Our experiments show that the rate of slab breakoff propagation controls both the duration of the pull force and the magnitude of pressure reduction. Our results further demonstrate that exhumation occurs where the slab breakoff propagation rate is lowest, rather than where the pull force is strongest, corresponding to where the slab tear initiates or terminates.
\end{abstract}

Keywords: Subduction, Exhumation, Slab breakoff, analogue models 2010 MSC: 00-01, 99-00

\section{Introduction}

Crustal rocks metamorphosed at ultra-high pressure (UHP) record burial to $100-150 \mathrm{~km}$ depths and subsequent return to the surface (Liou et al., 1994.

\footnotetext{
*Corresponding author: david.boutelier@newcastle.edu.au
} 
Chopin, 2003). Although it is well accepted that UHP rocks are formed by deep

5 subduction of continental passive margin rocks, the mechanisms by which these rocks are exhumed remain debated (e.g. Chemenda and Mattauer, 1995, Burov et al. 2001, Gerya et al., 2002).

a

Detachment of subducted oceanic lithosphere was proposed by Davies and von Blanckenburg (1995) to trigger buoyancy-driven exhumation of crustal material. The positive buoyancy of the subducted continental crust opposes the negative buoyancy of the subducted oceanic lithosphere, causing down-dip tension in the subducted slab and eventually breakoff. The subducted crustal material then rises up between the plates owing to its positive buoyancy. This conceptual model is supported by geological observations insofar that slab breakoff events in the Alps and Himalaya are thought to have occurred within time periods that overlap with the time of formation and exhumation of UHP rocks (Handy et al., 2010, Replumaz et al., 2010, Capitanio and Replumaz, 2013).

However, modeling studies have shown that slab breakoff also removes the main force that produces the low interplate pressure condition required for coherent units of buoyant continental crust to be exhumed in between the plates (Boutelier et al., 2002, Li and Gerya, 2009). Numerical simulations further demonstrated that subduction of the buoyant continental crust causes a reduction of the net negative buoyancy of the subducted lithosphere which may lead to a reduction of the convergence rate (Duretz et al., 2011, van Hunen and Allen

25 2011). This causes in turn a reduction in viscous support of the subducted slab by the surrounding upper mantle and an increased temperature within the slab. Reduction of viscous support increases the down-dip tension in the slab, while temperature increase weakens it, and therefore both processes facilitate and accelerate slab breakoff. Simulations thus suggest that exhumation of UHP rocks should occur when the downward pull is the largest and interplate pressure the lowest, which is immediately prior to slab breakoff.

Multiple modelling studies have employed two-dimensional simulation techniques and/or did not consider the fact that slab breakoff may be diachronous, initiating in one location and propagating laterally like a zipper Wortel and 
35 Spakman, 2000). Therefore, how the lateral propagation of slab detachment might change the above mentioned conceptual model for exhumation of the subducted continental crust therefore remains unclear. In this study we present three-dimensional, thermo-mechanical analogue modelling experiments in which diachronous slab detachment occurs spontaneously and its effects on surface deformation are captured using high-frequency Particle Imaging Velocimetry Adam et al. 2005). We use the experimental results to provide insights on how slab breakoff propagation rate influences the exhumation of subducted continental crust.
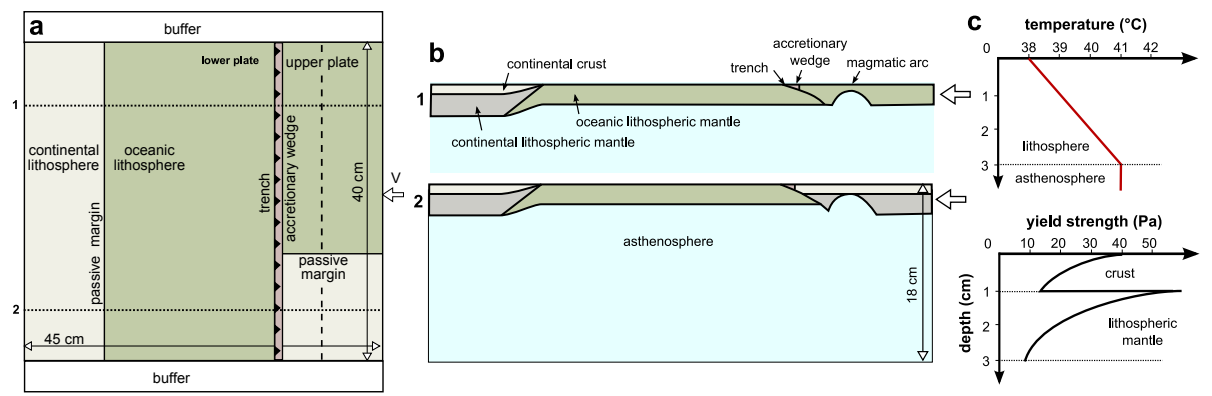

Figure 1: Schematic drawings of the model set-up in presented experiment. a: map view of the model showing the various oceanic and continental domains of both plates, and the buffers (weak neutrally buoyant material) along the sides. b: cross-sections 1 and 2 showing the model stratification and structure for oceanic and continental upper plate respectively. c: Temperature gradient in the model continental lithosphere and associated rheological stratification.

\section{Modeling technique}

The experiments comprise two lithospheric plates resting on low-viscosity asthenosphere (Fig. 1). The plates are made of temperature sensitive ductile elasto-plastic, strain softening materials that are subjected to a constant vertical thermal gradient, resulting in a reduction in plastic yield strength with depth in each layer (Fig. 1c) (Boutelier and Oncken, 2011). The subducting lower plate comprises two parts: an oceanic domain made of one single layer of negatively 
buoyant mantle lithosphere, and a two-layer continental domain comprising a positively buoyant continental crust and a neutrally buoyant lithospheric mantle. Between the continental and oceanic domains is a passive margin where the thicknesses of the crust and lithospheric mantle reduce progressively toward the oceanic domain (Fig. 1b). The boundary between the negatively buoyant oceanic mantle lithosphere and the neutrally buoyant continental mantle lithosphere dips towards the continent in the passive margin area in order for the buoyancy of the mantle to vary progressively across the margin (Fig. 1b). The upper plate includes an oceanic and a continental domain with a transition (margin) oriented perpendicular to the trench (Fig. 1a). This configuration is intended to correspond approximately to the Alpine collision bordered to the west by the subduction of the Tethys ocean underneath the Alkapeca oceanic arc (Handy et al., 2010, and references therein). The lithospheric upper plate includes a magmatic arc where the plate thins as suggested by petrological, geothermal and seismic data (Furukawa, 1993; Zhao et al. 1994, Schmidt and Poli, 1998). The tip of the overriding plate is made of a weak, buoyant material representing the accretionary prism. Convergence is driven by a piston pushing the upper plate at a constant rate while a Particle Imaging Velocimetry system is employed to monitor surface displacement and strain (Adam et al. 2005) with

70 high spatial and temporal resolution. The scaling factors and parameters values employed in the models and corresponding values in nature are provided in Table 1. Scaling and experimental procedures are described in details in Boutelier and Oncken (2011).

\section{Model Results}

We carried out over 20 experiments with various initial parameters and boundary conditions to explore multiple aspects of diachronous slab breakoff (see Boutelier and Cruden, 2016). Below we describe in details the experiment that best illustrate a newly-found relationship between the rate of lateral propagation of slab detachment and exhumation of buoyant continental crust and 
Table 1: Parameter values adopted for the model and nature. $\sigma$ is the plastic yield averaged over the layer thickness. subscript c, m, o, and a indicate crust, continental mantle lithosphere, oceanic mantle lithosphere and asthenosphere respectively. $\rho$ is the density, $\kappa$ is the thermal diffusivity, $V$ is the velocity and $t$ is the time.

\begin{tabular}{lccc}
\hline Parameter & Model & Nature & Scaling Factor \\
\hline$\sigma_{c}(\mathrm{~Pa})$ & 20 & $2.3 \times 10^{8}$ & $8.79 \times 10^{-8}$ \\
$\sigma_{m}(\mathrm{~Pa})$ & 20 & $2.3 \times 10^{8}$ & $8.79 \times 10^{-8}$ \\
$H_{c}(\mathrm{~m})$ & $1 \times 10^{-2}$ & $3.5 \times 10^{4}$ & $2.86 \times 10^{-7}$ \\
$H_{m}(\mathrm{~m})$ & $2 \times 10^{-2}$ & $7 \times 10^{4}$ & $2.86 \times 10^{-7}$ \\
$H_{o}(\mathrm{~m})$ & $2 \times 10^{-2}$ & $7 \times 10^{4}$ & $2.86 \times 10^{-7}$ \\
$\rho_{c}\left(\mathrm{~kg} \mathrm{~m}^{-3}\right)$ & $8.7 \times 10^{2}$ & $2.7 \times 10^{3}$ & $3.08 \times 10^{-1}$ \\
$\rho_{m}\left(\mathrm{~kg} \mathrm{~m}^{-3}\right)$ & $1.0 \times 10^{3}$ & $3.25 \times 10^{3}$ & $3.08 \times 10^{-1}$ \\
$\rho_{o}\left(\mathrm{~kg} \mathrm{~m}^{-3}\right)$ & $1.03 \times 10^{3}$ & $3.33 \times 10^{3}$ & $3.08 \times 10^{-1}$ \\
$\rho_{a}\left(\mathrm{~kg} \mathrm{~m}^{-3}\right)$ & $1.0 \times 10^{3}$ & $3.25 \times 10^{3}$ & $3.08 \times 10^{-1}$ \\
$\kappa\left(\mathrm{m}^{2} \mathrm{~s}^{-1}\right)$ & $2.8 \times 10^{-8}$ & $1 \times 10^{-6}$ & $2.8 \times 10^{-2}$ \\
$V\left(\mathrm{~m} \mathrm{~s}^{-1}\right)$ & $1.25 \times 10^{-4}$ & $1.25 \times 10^{-9}$ & $9.8 \times 10^{4}$ \\
$t(\mathrm{~s})$ & 92 & $3.15 \times 10^{13}$ & $2.92 \times 10^{-12}$ \\
\hline
\end{tabular}


summarize the results from other experiments.
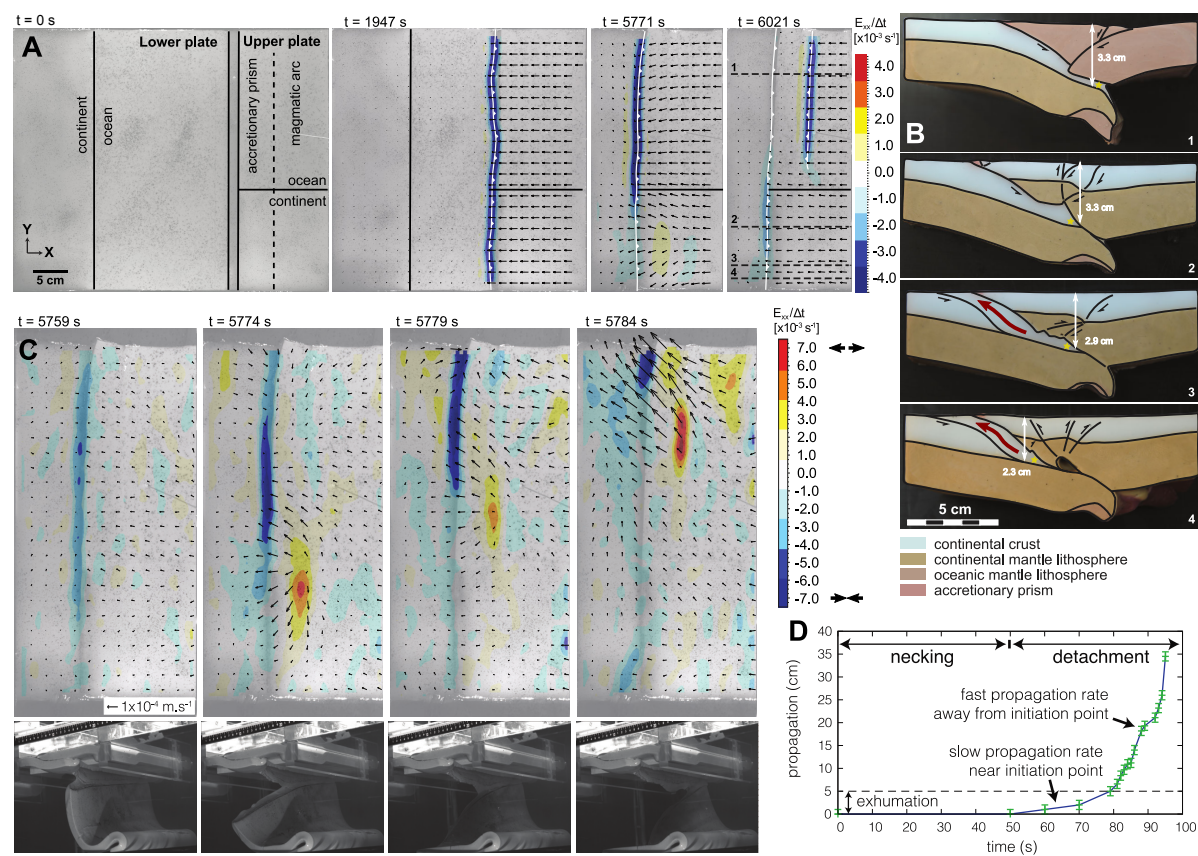

Figure 2: Evolution of the presented experiment from PIV monitoring and vertical crosssection in the frozen model; a: model surface views with PIV velocity vectors and derivative (i.e. strain rate), at four successive stages; $\mathbf{b}$ : vertical sections corresponding to lines 1 to 4 (panela). The yellow star indicates the approximate depth of the tip of the subducted crust. The red arrow illustrates the exhumation path; c: Successive view of model surface with PIV vectors and derivative during propagation of the slab detachment, and oblique side views (note the buffers); d: propagation of the slab tear derived from displacement of strain peak. Exhumation occurred within $5 \mathrm{~cm}$ of the model edge.

\subsection{Long-term consequence of slab detachment}

We first highlight the long-term consequence of slab breakoff on upper plate deformation. The velocity field was calculated using images taken $20 \mathrm{~s}$ apart and the calculation was performed for the entire duration of the experiment (Fig. 2a). The model was shortened for via subduction of the lower plate oceanic domain, and at $\sim 4700 \mathrm{~s}$, the passive margin entered the subduction zone (Fig. 2a). This event generally resulted in a switch from tension to compression in the upper 
plate and sometimes caused significant deformation in the arc and backarc areas (e.g. Chemenda et al. 2001). In the presented experiment, the negative buoyancy of the subducted slab was sufficient to prevent large deformation during the early stages of continental subduction (Fig. 2a). Shortly after initiation of continental subduction, the subducted slab touched the rigid base of the experimental tank. At $5734 \mathrm{~s}$, slab breakoff initiated near the warmer and weaker edge of the slab and rapidly propagated laterally across the model. The slab was rapidly tal compression. Forward and backward thrusts formed in the magmatic arc in the continent-continent collision zone (Fig. 2a,b). In the arc-continent collision area, slab breakoff also caused an increase in horizontal compression leading to the formation of one single backthrust in the magmatic arc area (Fig. 2a). This newly formed backthrust allowed the backarc oceanic lithosphere to be subducted, with the newly formed slab starting to cut through the remnants of the previous slab (Fig. 2b, profile 1) as observed in previous isothermal analogue experiments of subduction polarity reversal (Chemenda et al. 2001). However, the experiment was stopped before the subduction polarity reversal was completed.

The vertical sections in the model after deformation revealed thrusts formed in the subducting crust near the edge of the model. In this area, the passive margin was not subducted as deeply as the rest of the model. Since subduction of the passive margin in the arc-continent collision zone stopped immediately after break-off at the expense of shortening in the magmatic arc (Fig. 2a), the observed crustal structure is not merely a crustal duplex but requires that the passive margin was subducted to $>3 \mathrm{~cm}$ depth (equivalent $100 \mathrm{~km}$ in nature) when break-off occured to be subsequently exhumed. The PIV analysis confirms that this crustal structure formed during slab detachment (horizontal contraction in front of the trench in Fig. 2a at $\mathrm{t}=5771 \mathrm{~s}$ ). Although we do not observe the continental crust rising up in between the plates directly, we interprete the crustal structure in the interplate zone to be a product of exhumation. A similar crustal structure was obtained in previous analogue and numerical modeling experiments of continental subduction in the low interplate pressure 
regime (Chemenda and Mattauer, 1995, Boutelier et al., 2002, Boutelier and

120 Chemenda, 2008, Li and Gerya, 2009). We note that our modelling technique does not allow the formation and exhumation of buoyant melanges of metasediments and fragments of oceanic crust in the subduction channel because these units would be too small.

\subsection{Signature of propagating slab detachment}

To investigate how slab breakoff propagation impacted the subducted crust we calculated the surface velocity field and associated spatial derivatives (i.e. components of the strain rate tensor) with images taken only $1 \mathrm{~s}$ apart, allowing us to resolve the lateral propagation of the detaching slab (Fig. 2c). All experiments with spontaneous diachronous slab breakoff displayed a similar strain pattern, which traveled along the plate boundary (Boutelier and Cruden, 2016), characterized by an increase in horizontal trench-parallel and trenchperpendicular shortening in the trench/wedge area, followed by trench-parallel and trench-perpendicular extension in the forearc area (Fig. 2c). Oblique side views confirmed that this strain pattern is associated with the propagation of the slab tear (Fig. 2c). Ahead of the tear, the detached slab exerts an additional downward pull causing transient shortening in the forearc. Following the passage of the tear, both plates bounce upward due to elastic properties and isostasy, causing associated horizontal extension in the forearc. Experiments monitored with stereoscopic PIV demonstrate that the phase of horizontal shortening is associated with subsidence in the forearc basin, while the horizontal extension is associated with uplift (Boutelier and Cruden, 2016).

We used the migration of the pulses of extension and shortening together with oblique side views to estimate the slab breakoff propagation rate (Fig. 2cd). Breakoff started as a period of necking near the slab edge, followed by detachment with a rapidly increasing propagation rate. The detachment propagation rate was up to $\sim 20 \mathrm{~mm} / \mathrm{s}$ in the experiment illustrated here, which scales up to $600 \mathrm{~cm} / \mathrm{yr}$ in nature. In other experiments the scaled-up rate of propagation was up to $100 \mathrm{~cm} / \mathrm{yr}$ (Boutelier and Cruden, 2016). The main difference 
between experimental behaviours was the proximity of the model edge. In the experiment presented here, the rate increased significantly when the detachment approached the free edge of the model. The scaled-up rate of propagation obtained in our experiment is larger than the estimates from the migration of volcanism or magmatism (3-20 cm/year, Ferrari, 2004, Jolivet et al., 2015) or the migration of depocenters in forearcs $(7-45 \mathrm{~cm} /$ year, Meulenkamp et al. 1996, van der Meulen et al. 1998). Our scaled-up maximum propagation rate is also larger than rates previously obtained in isothermal analogue experiments ( $8 \mathrm{~cm} /$ year, Regard et al., 2005) but in agreement with the maximum rates obtained in 3D thermo-mechanical simulations $(80 \mathrm{~cm} /$ year, van Hunen and Allen, 2011) and analytical estimates (90 cm/year, Yoshioka and Wortel, 1995). We attribute our excessively high maximum propagation rate to the underestimated viscous support of the detached slab by the surrounding mantle, which would reduce the driving force and propagation rate.

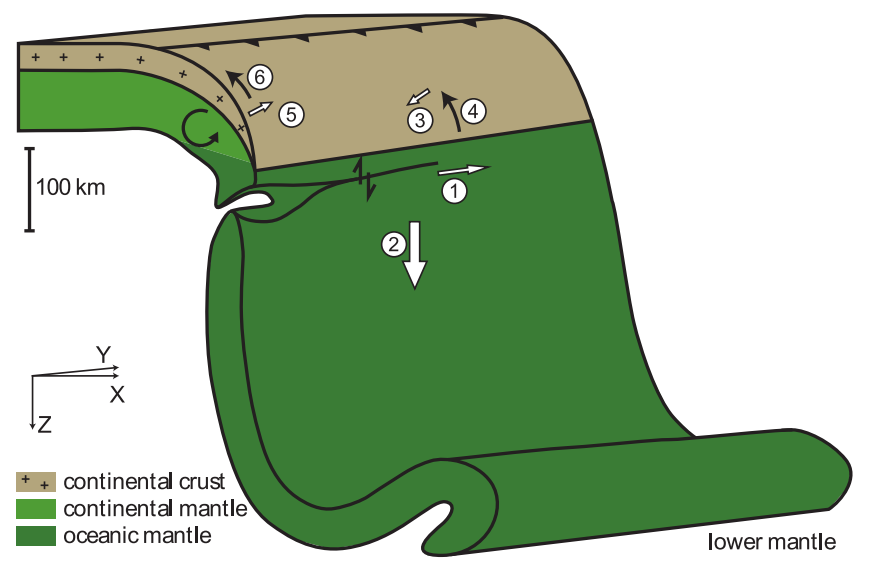

Figure 3: Illustration of proposed dual-mechanism exhumation of (U)HP rocks associated with propagating breakoff. 1: Horizontal propagation of detachment in the subducted lithosphere; 2: Excess slab pull generated ahead of the propagating tear; 3: Normal pull is produced on interplate zone causing reduction of pressure; 4: Pressure reduction allows buoyancy-driven exhumation of subducted crust; 5: After passage of tear, the lower plate bounces upward causing normal push on plate boundary and increase in interplate pressure; 6: Increased pressure terminates and crustal units are squeezed further upward. 


\section{Discussion}

\subsection{Change in plate kinematics associated with breakoff}

have triggered the subduction polarity reversal in the Alkapeka arc-continent 
collision west of the Alpine collision (Handy et al., 2010). By 30 Ma, sufficient shortening had been induced in the arc to initiate slab rollback and the formation of the western Mediterranean basins (Faccenna et al., 2001, Van Hinsbergen et al. 2014).

\subsection{Minimum rate of propagation}

Exhumation has been previously linked to an increase in the downward pull force, causing a reduction in the interplate pressure (Boutelier and Chemenda 200 2008, Li and Gerya, 2009). Our experiments suggest that the downward pull force increases during slab break-off propagation. As the length of the detached slab increases, it causes the excess downward pull ahead of the slab tear to increase as well. This is in agreement with the simulations of Guillaume et al. (2010), showing that the detaching segment of a slab causes a transient excess downward pull, which leads to a transient trench rollback if the trench is free to move (i.e. the arc is already rifted and a backarc spreading centre has formed). However, exhumation does not occur in our experiments where (or when) the pull is the largest but where slab breakoff propagation is the slowest, which is where the detachment initiates. Precisely, exhumation occurred within $5 \mathrm{~cm}$ from the model edge and the scaled-up rate of slab breakoff propagation was $>\sim 33 \mathrm{~cm} / \mathrm{yr}$.

First-order constraints from petrological and geochronological data allow for an independent estimate of maximum slab breakoff propagation rate. With exhumation rates of 1 to $3 \mathrm{~cm} /$ year and exhumation from 100 to 50 to $\sim 20 \mathrm{~km}$ depth (Chopin, 2003), the excess downward pull must last a minimum of 2.6 to $13 \mathrm{Myr}$ for the entire exhumation process to occur before the slab detachment has passed. Since the along-strike length of the area experiencing the downward pull is equivalent to $\sim 350 \mathrm{~km}$ in our models, the slab break-off propagation rate must be lower than 3.5 to $11.5 \mathrm{~cm} /$ year.

However, exhumation of continental rocks from 100 to $150 \mathrm{~km}$-depth may be the result of two successive processes (Fig. 3). Exhumation may be driven by buoyancy when the area undergoes the transient excess downward pull as- 
sociated with the passage of the slab tear. However, the exhumed units may only have ascended to depths of 50 to $70 \mathrm{~km}$. The second stage of exhumation may occur immediately after the passage of the slab breakoff, when the lower plate is pushed up due to a combination of buoyancy force and flexural rigidity, squeezing the rising UHP units upward within the subduction channel (Boutelier et al., 2002). In this scenario, the duration of the pull only needs to be 1 to $10 \mathrm{Ma}$ and the slab breakoff propagation rate is required to be lower than 3.5 to $35 \mathrm{~cm} /$ year. It is not possible to visualize the two stages of exhumation in our three-dimensional analogue experiments but a similar sequence of exhumation within the interplate zone has been previously observed and monitored in $2 \mathrm{D}$ analogue experiments (Boutelier et al., 2002) and numerical simulations (Li and Gerya, 2009).

The maximum propagation rate observed in our experiments (scaled up to $\sim 100 \mathrm{~cm} /$ year) are significantly greater than our estimates for maximum slab breakoff propagation rates allowing exhumation of deeply subducted continental crust ( $<35 \mathrm{~cm} /$ year). This explains why the deformation of the subducted crust and associated exhumation only occurs where the slab breakoff initiated. From its initiation point, the slab detachment propagates laterally with increasing rate (Fig. 2d). About $5 \mathrm{~cm}$ (equivalent to $175 \mathrm{~km}$ ) from the slab breakoff initiation point, the propagation rate has reached a threshold value precluding buoyancydriven exhumation. However, if slab detachment propagation rate was closer to the lowest estimates derived from geology ( 3 to $45 \mathrm{~cm} /$ year) (Meulenkamp et al. 245 1996, van der Meulen et al. 1998, Ferrari, 2004, Jolivet et al. 2015) or previous modelling studies (8 to $100 \mathrm{~cm} /$ year) (Regard et al., 2005; van Hunen and Allen, 2011), then the buoyancy-driven exhumation could occur over a longer length of the plate boundary, yielding larger HP or UHP terranes.

\section{Conclusions}

Three-dimensional thermo-mechanical laboratory experiments of continentcontinent and arc-continent collision with diachronous slab breakoff reveal that 
deeply subducted units are deformed and exhumed when the rate of propagation of slab breakoff is low. Slab detachment causes a transient excess downward pull in front of the propagating slab tear, which reduces the interplate pressure, process does not occur where the transient pull force is the strongest, but where it acts over the longest period of time, which is where the slab breakoff propagation rate is lowest.

Following slab breakoff, deformation in the upper plate is characterized by bivergent thrusts where the upper plate is continental or a new subduction zone localized within the arc where the upper plate is oceanic. High-pressure rocks exhumed in between the plates during the slab detachment may then be further squeezed up to shallower depths.

\section{Acknowledgments}

This research was supported by Newcastle University, Australia and Monash University, Australia.

\section{References}

Adam, J., Urai, J., Wieneke, B., Oncken, O., Pfeiffer, K., Kukowski, N., Lohrmann, J., Hoth, S., van der Zee, W., Schmatz, J., 2005. Shear localisation and strain distribution during tectonic faulting - new insights from granular-flow experiments and high-resolution optical image correlation tech-

ㅁ niques. Journal of Structural Geology 27, 283-301. doi:10.1016/j . jsg. 2004. 08.008 .

Boutelier, D., Chemenda, A., 2008. Exhumation of UHP/LT rocks due to the local reduction of the interplate pressure: Thermo-mechanical physical mod-

q elling. Earth and Planetary Science Letters 271, 226-232. doi:10.1016/j. epsl.2008.04.011. 
Boutelier, D., Chemenda, A., Jorand, C., 2002. Thermo-mechanical laboratory modelling of continental subduction: first experiments. Journal of the Virtual Explorer 6, 61-65.

Boutelier, D., Cruden, A., 2016. Slab breakoff: insights from 3D thermomechanical analogue modelling experiments. Tectonophysics doi 10.1016/ j.tecto.2016.10.020

Boutelier, D., Oncken, O., 2011. 3-D thermo-mechanical laboratory modeling of plate-tectonics: modeling scheme, technique and first experiments. Solid Earth 2, 35-51. doi:10.5194/se-2-35-2011.

Burov, E., Jolivet, L., Le Pourhiet, L., Poliakov, A., 2001. A thermomechanical model of exhumation of high pressure (HP) and ultra-high pressure (UHP) metamorphic rocks in Alpine-type collision belts. Tectonophysics 342, 113136. doi $10.1016 /$ S0040-1951(01)00158-5.

Capitanio, F., Replumaz, A., 2013. Subduction and slab breakoff controls on Asian indentation tectonics and Himalayan western syntaxis formation. Geochemistry, Geophysics, Geosystems 14, 3515-3531. doi 10.1002/ggge.20171

Chemenda, A., Mattauer, M., 1995. A mechanism for syn-collisional rock exhumation and associated normal faulting: results from physical modelling. Earth and Planetary Science Letters 132, 225-232.

Chemenda, A., Yang, R.K., Stephan, J.F., Konstantinovskaya, E., Ivanov, G., 2001. New results from physical modelling of arc-continent collision in „ Taiwan: evolutionary model. Tectonophysics 333, 159-178. doi 10.1016/ S0040-1951(00) 00273-0.

Chopin, C., 2003. Ultrahigh-pressure metamorphism: tracing continental crust a into the mantle. Earth and Planetary Science Letters 212, 1-14. doi 10.1016/ S0012-821X (03) 00261-9. 
Davies, J.H., von Blanckenburg, F., 1995. Slab breakoff: a model of lithosphere detachment and its test in the magmatism and deformation of collisional orogens. Earth and Planetary Science Letters 129, 85-102.

Duretz, T., Gerya, T.V., May, D.a., 2011. Numerical modelling of spontaneous slab breakoff and subsequent topographic response. Tectonophysics 502, 244256. doi $10.1016 /$ j.tecto.2010.05.024.

Faccenna, C., Becker, T.W., Lucente, F.P., Jolivet, L., Rossetti, F., 2001. History of subduction and back-arc extension in the Central Mediterranean.

ㅁ Geophysical Journal International 145, 809-820. doi 10.1046/j.0956-540x. $2001.01435 . x$.

Ferrari, L., 2004. Slab detachment control on mafic volcanic pulse and mantle heterogeneity in central Mexico. Geology 32, 77-80. doi 10.1130/G19887.1.

Furukawa, Y., 1993. Magmatic processes under arcs and formation of the

口 volcanic front. Journal of Geophysical Research 98, 8309. doi 10.1029/ 93JB00350.

Gerya, T.V., Stöckhert, B., Perchuk, A.L., 2002. Exhumation of high-pressure metamorphic rocks in a subduction channel: A numerical simulation. Tectonics 21, 6-1-6-19. doi:10.1029/2002TC001406.

Guillaume, B., Funiciello, F., Faccenna, C., Martinod, J., Olivetti, V., 2010. Spreading pulses of the Tyrrhenian Sea during the narrowing of the Calabrian slab. Geology 38, 819-822. doi 10.1130/G31038.1.

Handy, M.R., M. Schmid, S., Bousquet, R., Kissling, E., Bernoulli, D., 2010. Reconciling plate-tectonic reconstructions of Alpine Tethys with the geologicalgeophysical record of spreading and subduction in the Alps. Earth-Science Reviews 102, 121-158. doi:10.1016/j.earscirev.2010.06.002.

van Hunen, J., Allen, M.B., 2011. Continental collision and slab break-off: A 330 comparison of 3-D numerical models with observations. Earth and Planetary Science Letters 302, 27-37. doi $10.1016 / j$.epsl.2010.11.035 
Jolivet, L., Menant, A., Sternai, P., Rabillard, A., Arbaret, L., Augier, R., Laurent, V., Beaudoin, A., Grasemann, B., Huet, B., Labrousse, L., Le Pourhiet, L., 2015. The geological signature of a slab tear below the Aegean. Tectonophysics $659,166-182$. doi $10.1016 / j$.tecto.2015.08.004

Li, Z., Gerya, T.V., 2009. Polyphase formation and exhumation of high- to ultrahigh-pressure rocks in continental subduction zone: Numerical modeling and application to the Sulu ultrahigh-pressure terrane in eastern China. Journal of Geophysical Research 114, B09406. doi 10.1029/2008JB005935.

340 Liou, J.G., Zhang, R., Ernst, W.G., 1994. An introduction to ultrahigh-pressure metamorphism. Island Arc 3,1-24.

Mann, P., Taira, A., 2004. Global tectonic significance of the Solomon Islands and Ontong Java Plateau convergent zone. Tectonophysics 389, 137-190. doi: $10.1016 / j$.tecto 2003.10 .024 .

345 van der Meulen, M., Meulenkamp, J., Wortel, M., 1998. Lateral shifts of Apenninic foredeep depocentres reflecting detachment of subducted litho口 sphere. Earth and Planetary Science Letters 154, 203-219. doi 10.1016/ S0012-821X (97) 00166-0.

Meulenkamp, J., Kováč, M., Cicha, I., 1996. On Late Oligocene to Pliocene depocentre migrations and the evolution of the Carpathian-Pannonian system. Tectonophysics 266, 301-317.

Regard, V., Faccenna, C., Martinod, J., Bellier, O., 2005. Slab pull and indentation tectonics: Insights from 3D laboratory experiments. Physics of the Earth and Planetary Interiors 149, 99-113. doi:10.1016/j.pepi.2004.08.011.

Replumaz, A., Negredo, A.M., Guillot, S., Villaseñor, A., 2010. Multiple episodes of continental subduction during India/Asia convergence: Insight from seismic tomography and tectonic reconstruction. Tectonophysics 483, 125-134. doi:10.1016/j.tecto.2009.10.007 
Schmidt, M.W., Poli, S., 1998. Experimentally based water budgets for dehydrating slabs and consequences for arc magma generation. Earth and Planetary Science Letters 163, 361-379. doi:10.1016/S0012-821X (98)00142-3.

Scholz, C.H.C., Campos, J., 1995. On the mechanism of seismic decoupling and back arc spreading at subduction zones. Journal of Geophysical Research 100, 22,103-22,115. doi:10.1029/95JB01869.

Shemenda, A., 1994. Subduction: insights from physical modelling. Kluwer Academic Publishers, Dordrecht.

Van Hinsbergen, D.J.J., Vissers, R.L.M., Spakman, W., 2014. Origin and consequences of western Mediterranean subduction, rollback, and slab segmentation. Tectonics 33, 393-419. doi:10.1002/2013TC003349, arXiv:arXiv:1011.1669v3.

Wortel, M.J., Spakman, W., 2000. Subduction and slab detachment in the Mediterranean-Carpathian region. Science (New York, N.Y.) 290, 1910-1917. doi:10.1126/science.290.5498.1910

Yoshioka, S., Wortel, M., 1995. Three-dimensional numerical modeling of detachment of subducted lithosphere. Journal of Geophysical Research: Solid Earth 100.

Zhao, D., Hasegawa, A., Kanamori, H., 1994. Deep structure of Japan subduction zone as derived from local, regional, and teleseismic events. doi $10.1029 / 94 J B 01149$ 